\title{
LXXIII.
}

\section{Ueber die Braunsteinprobe.}

\author{
Von \\ A. Mevol. \\ (Journ. de Fharm. et de Chim. III. Série, Juill. 1846.)
}

(Auszug.)

Der Verfasser vervollständigt in Folgendem das früher in dieser Zeitschrift, Bd. XXVI, S. 151 bekannt gemachte Verfahren. Die Methode, von der die Rede sein soll, kniipft sich an folgende Reactionen :

1) $\mathrm{JnO}_{2}+2 \mathrm{Cl} \mathrm{H}+2 \mathrm{Fe} \mathrm{Cl}=\mathrm{Mn} \mathrm{Cl}+2 \mathrm{HO}+\mathrm{Fe}_{2} \mathrm{Cl}_{3}$.

2) $\mathrm{KO} \mathrm{ClO}_{5}+6 \mathrm{Cl} \mathrm{H}=\mathrm{K} \mathrm{Cl}+6 \mathrm{HO}+\mathrm{Cl}_{6}$.

Betrachtet man nun zunächst den zu untersuchenden Braunstein als durchaus rein $\mathrm{MnO}_{2}$ und wägt man davon eine Quantität ab, die unter dieser Voraussetzung 1 Litre Chlor mit Salzsäure entwickeln und daher 100 chlorometrischen Graden entsprechen müsste, so wird man, wenn man das aus der Probe reell entwickelte Chlor bestimmt, dessen Menge im Allgemeinen $=100-x$ finden. Man lässt dieses durch eine Eisenchlorürlösung absorbiren, welche so viel Eisenchlorür enthält, dass dadurch genau 1 Litre oder $100^{\circ}$ Chlor gebunden werden können. Diese Lösung, nachdem sie 100 - $x$ Chlor aufgenommen hat, wird mit einer Auflösung von chlorsaurem Kali, die für jedes Gramm einem Grade entspricht, behandelt, so dass die davon zur vollständigen Ueberfuhrung in Chlorid angewandte Menge ebenfalls $=\mathrm{x}$ ist und durch einfache Subtraction den Braunsteingehalt erkennen lässt.

Hat ein Braunstein z. B. 8,4 Grm. dieser Lösung von chlorsanrem Kali erfordert, so erhält man den Gehalt an reinem Braunstein aus folgender einfachen Betrachtung: 
Braunsteingehalt $+x$ Grm. Lösung von chlorsaurem hali $=100$ Chlorgraden

$\mathrm{x}$ oder durch chlorsaures Kali angezeigte Grade $=8,4^{\circ}$

Differenz oder gefundener Braunsteingehalt $=91,6^{\circ}$.

Man muss hier, wie in allen solchen Versuchen, wo man den Punct, wo ein Zusatz anfängt vorherrschend zu werden, erkennen muss, durch ein Mittel den Ueberschuss wahrnehmbar machen. Der Verf. wendet dazu das im Handel vorkommende Reagenzpapier an und vermehrt den unmittelbar gefundenen Gehalt um $0,5^{\circ}$, so dass diese Correction im obigen Beispiele $91,6^{\circ}+0,5^{\circ}$ $=92,1^{\circ}$ wird. Der Verfasser zieht es jetzt vor, die Lösung des chlorsauren Kali's zu messen, während er früher angegeben hatte, dass man diese wägen solle.

Will man nun ferner den Braunstein in Beziehung auf die Menge Salzsäure prüfen, die er erfordert, um eine gewisse Menge Chlor zu liefern, um zu erfahren, wie viel Salzsäure derselbe durch seine Beimengungen unnützerweise verbraucht, so ist unter den verschiedenen Verfahrungsweisen, die man dazı vorgeschlagen hat, die einfachste wohl noch diejenige, bej welcher man pruft, wie viel Marmor eine bekannte Menge Braunstein und eine ebenfalls bekannte Menge Salzsäure, nachdem sie erhitzt worden. und die flüchtigen Producte gesammelt und dem Gemisch wieder hinzugefügt wurden, aufzulösen vermag. Allein diese Methode ist dadurch fehlerhaft, dass der Marmor die Eisenoxydsalze fallt, die sich immer beim Mangan finden. Nach den folgenden Betrachtungen sucht der Verf. diese Uebelstände zu beseitigen. Nach Dal to n concentrirt sich eine Salzsäure beim Kochen, wenn sie weniger als 1,094 Dichte hat, und destillirt bei $100^{\circ}$ unverändert mit diesem spec. Gewicht. Man verdünnt die concentrirte Salzsäure daher mit ihrem gleichen Gewichte Wasser, wodurch sie sich jener Dichtigkeit nähert, die durch Verbindung mit dem Braunstein noch vermindert wird. Beim Kochen dieser so verdünnten Säure mit Braunstein erhielt der Verfasser eine Flüssigkeit als Destillat, welche $0^{\circ}$ B. zeigte und somit keine Salzsäure in merklicher Menge mit übergerissen hatte. Das. Verfahren, die Menge Salzsäure zu bestimmen, welche eine Braunsteinprobe bedarf, besteht nun darin, dass man diese Salzsäure, die man ohne Säureverlust kochen kann, mit Braunstein und Zusatz von metallischem 
Kupfer kocht, um das Eisen in Oxydul zu verwandeln und dadurch nachher die Fällung des Eisens durch kohlensauren Kalk za verhüten. Man kocht in einem Kolben, der durch einen Kork, durch welchen ein Rohr geht, verschlossen ist, giesst die Flüssigkeit, wenn sie farblos geworden ist, aus, verdünt sie mit Wasser, wodurch sie zugleich abkühlt, und sättigt mit Kreide, von einer gewogenen Menge derselben, so dass der Rest derselben, wenn man ihn wiederum gewogen hat, die verbrauchte Menge angiebt. Man kann demnach leicht in einem Braunstein den wirklichen Gehalt desselben und eben so die Menge Salzsäure, die durch diesen und durch die lösliche Gangart, die er enthält, verbraucht wird, bestimmen.

\section{LXXIV.}

Notiz über die Säure für die Probirnadeln.

\section{Von \\ A. Hevot.}

(Journ. de Fh. ct de Chim. III. Sćrie, Tom. X. Juill. 1846.)

Man verdankt Va uque li n die Ausmittelung der Beschaffenheit des Königswassers, welches man in der Goldprobirkunst anwendet. Von verchiedenen Seiten ist diese Flüssigkeit mit Unrecht allgemein zur Goldprobe benutzt, während $V$ a u qqu elin sie nur für die französischen Bijouteriewaaren, d. h. für Legirungen, die ungefähr 750 Tausendtel Gold enthalten, vorgeschlagen hat. Die Erfahrungen haben gelehrt, dass Goldwaaren von diesem, und um so mehr die von einem grösseren Gehalt an Gold, nicht von der Probeflüssigkeit angegriffen werden, welche dagegen schlechteres Gold angreift und auf dem Probirstein nur einen braunen glanzlosen Strich hinterlässt. Das Verhältuiss, in welchem diese Probeflüssigkeit gemischt wird, ist nach $\mathrm{Vau}$ que li n folgendes:

Salpetersäure von $1340($ Wasser $=1000)$ Dichtigkeit 98 Theile Salzsäure von 1173 Wasser 